\title{
Characterization and serotype distribution of Aggregatibacter actinomycetemcomitans isolated from a population of periodontitis patients in Spain.
}

María Mínguez ${ }^{1}$, Xiana Pousa ${ }^{1}$, David Herrera ${ }^{1,3}$, Andrea Blasi ${ }^{2}$, Mari Carmen Sánchez ${ }^{2}$, Rubén León ${ }^{2}$, Mariano Sanz ${ }^{1,3}$

${ }^{1}$ Section of Periodontology, Faculty of Odontology, University Complutense, Madrid, Spain.

${ }^{2}$ Laboratory of Research, Faculty of Odontology, University Complutense, Madrid, Spain.

${ }^{3}$ ETEP (Etiology and Therapy of Periodontal Diseases) Research Group, University Complutense, Madrid, Spain.

Correspondence: Dr. David Herrera. Section of Periodontology, Faculty of Odontology. University Complutense. Plaza Ramón y Cajal S/N. 28040 Madrid. Spain.

Tel: (+34) 913941907

Fax: (+34) 913941910

E-mail: davidher@ucm.es

Running title: $A a$ from periodontitis patients in Spain. 


\section{Introduction}

The etiology of periodontal diseases has been associated with microorganisms colonizing the subgingival biofilm. ${ }^{1}$ Among these, Aggregatibacter actinomycetemcomitans has received particular attention and it is regarded a major pathogen, being a key factor in the etiology of early onset and refractory forms of periodontitis. ${ }^{1-4}$ This notion is derived primarily from association studies, conducted in North America and Europe, which significantly correlated the presence and amount of these microorganisms with the presence and severity of disease and also linked a worse than expected treatment outcome with presence of high levels of $A$. actinomycetemcomitans after therapy. In prospective studies, its presence has also been identified as a risk factor for the onset of periodontitis. ${ }^{5}$ On the other hand, $A$. actinomycetemcomitans has also been frequently detected in subjects without clinical evidence of periodontal disease, what suggests that either not all subjects are equally susceptible or that there are variations in the virulence and the pathogenic potential of this microorganism.

Based on the presence of specific capsular proteins able to elicit a subject's differential antibody response, six serotypes (from "a" to "f") of $A$. actinomycetemcomitans have been identified. ${ }^{6}$ This genetic variability has been associated to differential virulence since A. actinomycetemcomitans serotype "b" has been linked to periodontitis lesions, while serotypes "a" and "c" demonstrated a stronger association with periodontal health. ${ }^{2,}$ 7-9 A similar serotype-dependent differential virulence has also been suggested for Porphyromonas gingivalis. ${ }^{10,11}$

The global $A$. actinomycetemcomitans serotype distribution is not homogeneous and the association between serotype and periodontal status may depend on the geographical location and/or ethnicity of the studied population. ${ }^{12-15}$ For example, Yang (2004) found that serotype " $b$ " was more often isolated in aggressive than chronic forms of periodontitis in a large population in Philadelphia. ${ }^{16}$ Although most studies suggest that $A$. actinomycetemcomitans colonization occurs through one unique serotype, others have shown infected subjects with two or three serotypes. ${ }^{7,17-20}$ 
A. actinomycetemcomitans has also demonstrated other forms of genetic diversity also linked to virulence traits, mostly in relation to its capacity to produce leukotoxin, a protein that specifically destroys human polymorphonuclear leukocytes. 21-23 There are, however, significant variations in the leukotoxin production demonstrated among different isolates. ${ }^{10,23}$ The mechanism by which the most virulent species produce high levels of leukotoxin was identified by a 530-bp deletion in the region upstream of the leukotoxin gene operon $(l x t)$, which encodes this protein, thus bringing a second strong promoter and producing high amounts of this toxin. The majority of strains of this highly leukotoxic clone were isolated from subjects of African descent. Haubek et al. demonstrated, in a population based longitudinal study of 700 adolescents, that the JP2 strain of A. actinomycetemcomitans was the etiological agent of the aggressive forms of periodontitis in adolescents living in or originating from North and West Africa. ${ }^{24}$ Individuals who carried the JP2 clone of $A$. actinomycetemcomitans had a significantly increased risk of periodontal attachment loss, either alone (relative risk 18.0) or together with the presence of non-JP2 clones of A. actinomycetemcomitans (12.4). A much less pronounced disease risk was found in those carrying non-JP2 clones only (3.0).

Another identified virulence factor associated to this bacterial species is the cytolethal distending toxin $(\mathrm{Cdt})$, which blocks the progression of the cell cycle in specific types of eukaryotic cells and other cell lines, specifically oral epithelial cells and $\mathrm{T}$ lymphocytes. This holotoxin, which has only been identified in $A$. actinomycetemcomitans isolated from the human oral cavity is made up of three subunit proteins designated as $\mathrm{CdtA}, \mathrm{CdtB}$ and $\mathrm{CdtC}$ and different studies have reported that this cytotoxic Cdt activity is also heterogeneous among A. actinomycetemcomitans isolates. In a study by Ahmed et al, $86 \%$ of $A$. actinomycetemcomitans isolates presented the complete operon and its characteristic cytotoxic activity. ${ }^{25,26}$ Tan et al. showed a close association between aggressive forms of periodontitis and $A$. actinomycetemcomitans strains positive to the Cdt genotype. ${ }^{27}$

In summary, numerous studies have shown that the genetic diversity in $A$. actinomycetemcomitans strains may be associated to geographical diversity, thus suggesting a differential virulence. ${ }^{7,9,21,28,32}$ Since there are no studies in Southern 
Europe evaluating the differential virulence of $A$. actinomycetemcomitans isolates in periodontitis patients, it is the objective of this investigation to study the serotype distribution of $A$. actinomycetemcomitans, the variation in the sequences of the genes that codify the leukotoxin and the distribution of the $c d t$ operon in periodontitis patients in Spain.

\section{Material and methods}

\section{Patient selection and sample reception}

The bacterial isolates used in this study were obtained from a consecutive series of subgingival microbial samples from Spanish patients sent to the Laboratory of Microbiology at Faculty of Odontology, University Complutense, Madrid, Spain, for microbial diagnosis over 18 months from January 2007 to July 2008. The patient residence was Spain and ethnicity Caucasian in all cases. All samples were taken from patients as part of their periodontal diagnostic process, and they were informed about the benefits of the microbiological diagnosis, an overview of the microbiological procedures and that, eventually, some of the cultured colonies could be isolated for further processes, including definitive identification. Verbal consent was obtained from all patients.

Samples from patients with a clinical diagnosis of chronic or aggressive untreated periodontitis according to the American Academy of Periodontology 1999 classification were included. ${ }^{33}$ Sample from patients categorized as "refractory" periodontitis as a separate group were also included, when these subjects had a recurrence of disease after treatment or when the treatment outcome was not appropriate.

These microbiological samples were collected by periodontists in private practices as well as by postgraduate students in the Postgraduate Clinic of Periodontology in the same Faculty of Odontology. Each sample was accompanied by clinical information including patient age, gender, clinical diagnosis, brief clinical and drug intake history, smoking status, sample sites and time and date of sampling. The 
clinical parameters: probing pocket depth (PPD), gingival recession, presence or absence of plaque (PI), bleeding on probing (BOP) and suppuration were recorded at the four selected sites from which samples were taken. These sites represented the deepest pocket with bleeding in each quadrant and after careful removal of supragingival plaque and isolation with sterile cotton rolls and gentle air drying, two consecutive sterile paper points (medium size, Maillefer, Ballaigues, Switzerland) were inserted as deep as possible in the pocket, and left in place for 10 seconds. ${ }^{34}$ The paper points were transferred to a vial containing $1.5 \mathrm{ml}$ of Reduced Transport Fluid (RTF), and pooled with all the other paper points. ${ }^{35}$ The vial was sent to the laboratory and processed within 24 hours.

Only samples were selected when belonging to patients with at least four sites with (PPD) deeper than $4 \mathrm{~mm}$ and clinical attachment loss (CAL) higher than $4 \mathrm{~mm}$. Samples from subjects with fewer than 16 teeth and from patients who had taken any antibiotic medication within the previous three months were excluded.

\section{Culture, isolation and storage}

Samples were homogenized with a vortex and 10-fold serially diluted in Phosphate sodium buffer (PBS) and aliquots of $100 \mu 1$ were plated in two different media: Blood agar medium (No. 2 of Oxoid; Oxoid Ltd., Basingstoke, England), with 5\% horse blood, and haemin (5 mg/l) and menadione (1 mg/l) and Dentaid-1 medium. ${ }^{36}$

Blood agar plates were studied after 7 and 14 days of anaerobic incubation (80\% $\mathrm{N}_{2} ; 10 \% \mathrm{H}_{2} ; 10 \% \mathrm{CO}_{2}$ at $37^{\circ} \mathrm{C}$ ). Plates were carefully examined and based on the morphology of the isolated colonies the following pathogens were identified: $P$. gingivalis, Prevotella intermedia/nigrescens, Tannerella forsythia, Parvimonas micra, Capnocytophaga spp., Eikenella corrodens and Fusobacterium spp. Colonies from each pathogen were counted as the total number from a representative plate (between 30 to 300 colonies). The specific media, Dentaid-1 was used for the selective isolation and growth of $A$. actinomycetemcomitans. Plaques with this media were incubated at $37^{\circ} \mathrm{C}$ in air with 5\% CO2 and after 3-5 days were carefully examined for the identification of A. actinomycetemcomitans. This identification was based on its typical colony morphology, a catalase reaction and a set of specific enzymes (Rapid ID, NH system 
Romel Inc, USA). One to three isolates per subject were subcultured and purified. All original samples were stored at $-80^{\circ}$ until further use. Only positive isolates for $A$. actinomycetemcomitans were included in this investigation.

\section{Isolation of genomic DNA}

Bacterial cells were collected after centrifugation and re-suspension in $1 \mathrm{ml}$ of tris- $\mathrm{HCl}$ $10 \mathrm{mM}$, EDTA $0.8 \mathrm{mM}$ (ph 8.0) and lysozyme (final concentration $5.0 \mathrm{mg} / \mathrm{ml}$ ). They were then incubated at $37{ }^{\circ} \mathrm{C}$ for $30 \mathrm{~min}$ and proteinase $\mathrm{K}$ was added until reaching a final concentration of $2 \mathrm{mg} / \mu \mathrm{l}, 1 \mathrm{mg} / \mu \mathrm{l}$ and $1 \%$, respectively. ${ }^{37}$ The DNA was then extracted with equal volumes of phenol (saturated with $10 \mathrm{mM}$ Tris- $\mathrm{HCl}, \mathrm{pH} \mathrm{8.0)}$ ) and phenol- chloroform-isoamyl alcohol (25:24:1). Bulk nucleic acids were precipitated from the solution using ethanol followed by centrifugation $(12.000 \mathrm{rpm})$ for $10 \mathrm{~min}$. The DNA precipitate was re-suspended in $50 \mu \mathrm{l}$ of sterile distilled water. The result of the DNA extraction was assessed by electrophoresis. A $5 \mu 1$ aliquot of extracted DNA was electrophoresed through a $1.0 \%$ agarose gel, in a tris- Acetate EDTA (TAE) buffer. The gel was stained with ethidium bromide $(10 \mu \mathrm{g} / \mathrm{ml})$ and visualized under UVillumination.

\section{Serotyping of strains}

Serotypes "a" to "f" were determined by the PCR technique, based on specific sequences from the gene clusters responsible for the distinct serotypes. The PCR reaction was performed with the specific primers described by Kaplan for the identification of the serotypes "a" to " $\mathrm{f}$ ". ${ }^{6}$ The sequences of the primers used are listed in Table 1 . The PCR reaction was performed in a $25 \mu$ final volume containing $2.5 \mu \mathrm{l}$ of $10 \mathrm{x}$ PCR buffer, $1.0 \mu \mathrm{l}$ of $25 \mathrm{mM} \mathrm{MgCl}_{2}, 0.5 \mu \mathrm{l}$ of $10 \mathrm{mM}$ deoxynucleoside triphosphates, 0.5 U Taq DNA polymerase (Invitrogen Corporation, CA, USA), $1.0 \mu 1$ of $25 \mu \mathrm{M}$ primers and $2 \mu \mathrm{l}$ of genomic DNA. A $15 \mu \mathrm{l}$ aliquot of each PCR is electrophoresed through a $1.0 \%$ agarose gel in $1 \mathrm{X}$ TAE buffer, the PCR products are visualized by staining with ethidium bromide $(10 \mathrm{mg} / \mathrm{ml})$ and visualized under UV illumination. These PCR assays were performed including positive and negative controls in an iCycler Thermal Cycler (Bio-Rad Laboratories, Inc). After the initial step of denaturation at $96^{\circ} \mathrm{C}$ for $3 \mathrm{~min}$, a total of 35 PCR cycles were performed; each cycle consisted of $30 \mathrm{~s}$ of denaturation at $95^{\circ} \mathrm{C}, 1 \mathrm{~min}$ of annealing at $55^{\circ} \mathrm{C}$ and $72^{\circ} \mathrm{C}$ for 2 min, and a final step of extension at $72{ }^{\circ} \mathrm{C}$ for $10 \mathrm{~min}$. 


\section{Detection of putative leukotoxin overproducers}

The deletion of $530 \mathrm{bp}$ in the promoter region of the leukotoxin gene was determined in every isolate by means of PCR. The PCR primers and conditions for detecting the JP2 strain were those described by Haubek et al. ${ }^{30}$ The PCR reaction was performed in a 25 $\mu$ final volume containing $2.5 \mu \mathrm{l}$ of $10 \mathrm{x}$ PCR buffer, $1.0 \mu \mathrm{l}$ of $25 \mathrm{mM} \mathrm{MgCl} 2,0.5 \mu 1$ of $10 \mathrm{mM}$ deoxynucleoside triphosphates, $0.5 \mathrm{U}$ Taq DNA polymerase (Invitrogen Corporation, CA, USA), $1.0 \mu \mathrm{l}$ of $25 \mu \mathrm{M}$ primers and $2 \mu \mathrm{l}$ of genomic DNA.

PCR primer upstream from the deletion had the sequence 5'CAGATCAAAACCTGATAACAGTATT-3', and the primer downstream from the deletion had the sequence 5'TTTCTCCATATTCCCTCCTTCTGT-3'.The PCR temperature profile included an initial step of denaturation at $94{ }^{\circ} \mathrm{C}$, a total of 30 cycles of denaturation for $1 \mathrm{~min}$ at $94^{\circ} \mathrm{C}$, annealing for $1 \mathrm{~min}$ at $60^{\circ} \mathrm{C}$, and a final step of extension at $72^{\circ} \mathrm{C}$ for $2 \mathrm{~min}$. The PCR fragment of $504 \mathrm{bp}$ indicated deletion of $530 \mathrm{bp}$ corresponding to the JP2 strain whereas a PCR fragment of 1034 bp indicated no deletion in the A. actinomycetemcomitans leukotoxin operon. Positive and negative controls were included in the PCR. The molecular weights of the PCR products were determined by visualization and comparison with standard molecular weight markers using agarose gel electrophoresis.

\section{cdt detection}

The distribution of the $c d t$ operon was also determined by means of PCR using the same procedure previously described for Ltx but using the primers that amplify the complete operon $c d t \mathrm{~A} 1$ and $c d t \mathrm{C} 2$, which are listed in Table 2. The total molecular weight of the amplified segment was of 2016 bp when the complete operon was present. The PCR products were also determined by visualization in $1.0 \%$ agarose gel.

\section{Data analyses}

Descriptive statistics, including frequency distribution were used to characterize the sample in terms of the different serotypes, the variation in the sequences of the genes that codify the leukotoxin and the distribution of the $c d t$ operon. Further subgroup analysis was performed to assess the differences in serotype, leukotoxin and $c d t$ gene over-production according to the different clinical diagnoses: chronic, aggressive or 
refractory, as well to other clinical and patient variables.

For continuous variables, ANOVA test was used to compare different disease categories, with the multiple rank test as the post hoc test. For categorical variables, contingency tables were constructed and compared by means of chi-square test. The software used for the analyses was Statgraphics Plus 5.1 (Statpoint Technologies, Inc., Warrenton, VA, USA).

\section{Results}

\section{Demographics}

From a total of 701 patient samples processed, 396 samples were taken in 25 private practices throughout Spain (16 were located in Madrid area), and 305 from patients seeking treatment in the Section of Periodontology, Faculty of Odontology, University Complutense, Madrid, Spain. Out of these 701 patients, 40 (5.7\%) fulfilled the inclusion criteria and were positive for $A$. actinomycetemcomitans. These patients had a mean age of 45.2 years (ranging 24-68) and were predominantly non-smokers $62.5 \%$ (25). They were stratified in three groups according to their periodontal condition and $19(47.5 \%)$ were diagnosed of chronic periodontitis, $13(32.5 \%)$ of aggressive periodontitis and 8 $(20 \%)$ of "refractory" periodontitis. "Refractory" periodontitis patients had significantly more recession $(p=0.010)$ and shallower pockets (tendency towards statistical significance, $\mathrm{p}=0.051)$ than chronic and aggressive periodontitis patients. Similar CAL levels (7.5-7.7 mm), BOP proportions (78-85\%) and plaque index (40-45\%) were observed among the three patient groups. Patients with aggressive periodontitis were significantly younger $(p<0.001)$ than chronic periodontitis or refractory patients. The detailed periodontal status, clinical and demographic variables of these 40 patients are depicted in Table 3. No differences among the three groups were observed for either smoking or gender (Table 4).

\section{Patient-based results}

Serotype distribution (Table 4) 
Overall, $75 \%$ of the patients were characterized by a unique serotype, while $17.5 \%$ harbored two serotypes and in $7.5 \%$ of the patients the serotype could not be characterized (although A. actinomycetemcomitans was confirmed by PCR using different primers). In the patients where a unique serotype was identified, "a" or "b" serotypes were detected in $60 \%$ of the patients, while in those patients with more than one serotype, 4 different co-colonization profiles were detected, with 1-3 patients each.

When assessing the serotype distribution according to clinical diagnosis, refractory patients showed a clear predominance of serotype "b" (either alone in 50\% of the cases, or combined with serotype "a" in $25 \%$ of the patients) and the frequent presence of more than one serotype (37.5\%). In aggressive periodontitis, monocolonization with "a" and "b" serotypes occurred in $25 \%$ and $35 \%$ of the cases, respectively. A less clear pattern was observed for chronic periodontitis, with similar figures for serotypes "a", "b", "c", not-typeable and co-colonization.

\section{cdt operon detection (Table 4)}

Cdt positive samples were identified four times more frequently. Presence of Cdt positive and negative isolates in the same patient was observed in $28 \%$ of the cases. No Cdt negative samples were observed in refractory patients, while in chronic periodontitis there was also a clear predominance of Cdt positive profiles (67\%).

\section{lktC promoter deletion}

No highly leukotoxic JP2 strains (identified by the presence of a 530-bp deletion in the promoter region of the $l k t \mathrm{C}$ gene of $A$. actinomycetemcomitans) were identified in this studied population. In all the isolates, a clear band in the $1.0 \%$ agarose gel, equivalent to a molecular weight of 1034-bp was observed.

\section{Strain-based results}

From the 40 positive samples, 79 strains were isolated and studied corresponding to serotype "a", 24 strains (30.4\%), to serotype "b", 30 strains (38\%), to serotype "c", 12 samples $(15.2 \%)$ and to serotype "d", 4 samples (5.1\%). Mono-colonizations with serotypes "e" or "f" were not identified and the serotype could not be determined in 9 of these strains $(11.4 \%)$. All strains were positive for the ltx gen. The $c d t$ gene was 
detected in 52 out of the 79 strains of periodontitis patients $(65.8 \%)$.

The distribution of the $c d t$ gen among different serotypes (Table 6) showed a clear predominance of $c d t$ positive strains in serotype "a" and, to a lesser extent, in serotype "c", while an almost even distribution was observed for serotypes "b" and "d". The differences between serotypes " $a$ " and " $b$ " were statistically significant $(p=0.042)$.

\section{Discussion}

The main findings of this investigation show that among the 40 patients where $A$. actinomycetemcomitans was detected $75 \%$ carried a unique serotype, while $17.5 \%$ were colonized by two serotypes. The most predominant serotypes were "a" and " $b$ " and none of the isolates were highly leukotoxic strain JP2 and while $65.8 \%$ were positive for the $c d t$ gen.

Using bacterial culturing the obtained prevalence of $A$. actinomycetemcomitans in this adult periodontitis population from Spain was of 5.7\%. Previous reports from our research group have shown similar prevalence data using culture $(6.3 \%)$ in a similar Spanish population, although using PCR methods the prevalence rose to $18.8 \%{ }^{38} \mathrm{~A}$ similar low prevalence (3.2\%) was also reported when studying a comparable population in Spain, but with the use of different culture medium (TSVB Tryptic soyserum- bacitracin-vancomycin), ${ }^{39}$ also reporting a low recovery rate. ${ }^{36}$ In other geographical locations, the reported prevalence of $A$. actinomycetemcomitans in periodontitis patients varies substantially depending on the microbial detection technologies used, with proportions ranging between $3 \%$ to $38 \%$ in United States of America and $15 \%$ in Sri Lanka when using immunofluorescence. ${ }^{37-40}$ With the use of bacterial culturing the reported prevalence of A. actinomycetemcomitans has varied between $5.4 \%$ in a group of aggressive periodontitis patients in Jamaica to $18 \%$ in Germany or $54.4 \%$ in Ghana. ${ }^{41-43}$ These prevalence can rise to $83 \%$ in China and to 93\% in Thailand when using DNA-DNA checkerboard hybridization. ${ }^{44-45}$ With PCR the reported prevalence was $23.5 \%$ in United States of America, $19 \%$ in a Thai population, between $17.5 \%$ and $25 \%$ in Brazil, from $30 \%$ to $47.7 \%$ in Germany, $26.7 \%$ 
in Korea, $27.5 \%$ in a Greek population and $44 \%$ in Haiti. ${ }^{42,46-53}$

From the $40 \mathrm{~A}$. actinomycetemcomitans-positive samples studied, 79 strains were isolated and studied, being the serotype " $b$ " the most frequent, followed by serotype "a", both representing $68.4 \%$ of all the strains. These findings are in accordance with other studies assessing populations from different geographical locations, which have also reported predominance in A. actinomycetemcomitans serotypes "a", "b", and "c", including Germany. ${ }^{54}$ In the United States of America, serotype "b" strains were more frequently isolated from patients with localized juvenile periodontitis (LJP) when compared to other periodontal conditions or periodontally healthy subjects. ${ }^{7,9}$ Listgarten et al. reported that elevated antibody responses to serotype "a" were more common in chronic periodontitis patients. ${ }^{55} \mathrm{In}$ this investigation, we have identified not only a higher percentage of serotype "a" strains in chronic periodontitis patients, but also in aggressive periodontitis patients, in which the most common is the serotype "b", like in the refractory periodontitis group. On the contrary, Dogan et al. reported that serotype "a" was the most frequent serotype in LJP subjects while in adult periodontitis subjects no differences among the serotypes "a", "b" and "c" were reported. 56 A higher frequency of serotype "b" was reported in Finnish patients with periodontitis, while "c" was more often related to periodontally healthy subjects. ${ }^{9,20}$ In Asian populations, such as in Korea and Japan or in European countries, such as in Greece, the serotype "c" was also frequently associated with periodontally affected sites. 19,20,52,57 Strains with serotypes “d", "e" and strains without detectable serotype were also identified in Japanese subjects in proportions of 5\%, 23\% and $10 \%$, respectively. ${ }^{18,56}$ These serotypes are less frequently found than "a", "b" and “c" serotypes. ${ }^{10,17,18,56,58}$

This investigation demonstrated that the genes responsible for the codification of the Ltx were present in all the strains (100\%), but none showed the JP2 clone responsible of the highly leukotoxic strains. These highly virulent $A$. actinomycetemcomitans strains have been detected mainly in subjects of African origin, with proportions of $8.8 \%$ reported in Ghana adolescents and $77 \%$ in Moroccan patients with a diagnosis of aggressive periodontitis and with a higher risk of periodontal attachment loss. ${ }^{43}, 59 \mathrm{JP} 2$ clone strains have also been reported in other distant 
geographical populations, such as in Thailand, but has been found to be absent in Greece. ${ }^{47,51}$ In a German population, and using PCR, the JP2 clone was found to be present in 2 out of $99(2 \%)$ of the recruited patients and, in both cases, the subjects were immigrants of African origin suffering from chronic periodontitis. ${ }^{54}$ Using a characterization method of point mutations within housekeeping genes and pseudogenes, Haubek et al. developed a model of global spreading of the JP2 clone. ${ }^{60}$ According to this model, the patterns of mutation suggest that the JP2 clone emerged from a distinct genotype in the Mediterranean Africa approximately 2400 years ago and spread subsequently to West Africa and to other parts of the world. In fact, in Brazil colonization by highly leukotoxic A. actinomycetemcomitans was associated with increased periodontitis severity. ${ }^{38}$ Even though JP2 clone strains have almost been exclusively detected among individuals in North-Africa or from African descent limited information is still available regarding the microbiological status of this clone in Caucasians. In fact, this study has shown that a Spanish population, although being in close relation to North African populations (namely, Moroccan populations), due to geographical and immigration factors, did not harbor any highly leukotoxic strains.

This investigation also evaluated the third factor of genetic variability of $A$. actinomycetemcomitans, the $c d t$ gene, being detected in $65.8 \%$ of the strains from periodontitis patients. The reported prevalence of this toxin in $A$. actinomycetemcomitans strains is highly variable. It has been found to be present in $45.5 \%$ of a chronic periodontitis patient sample in Germany. ${ }^{54}$ Ahmed et al. found 43 of 50 strains from periodontitis patients contained all three $c d t$ genes and expressed Cdt activity. ${ }^{26}$ Similarly, Fabris et al. reported Cdt activity in 39 out of 40 patients. ${ }^{61}$ In another study, however, only 13 out of 106 diseased sites were positive for these genes. $^{28}$

It is important to highlight the limitations of the present observational study, since a limited number of strains were studied and due to the low prevalence of $A$. actinomycetemcomitans in Spanish periodontitis patients the obtained associations only allowed us to generate hypothesis, rather than to establish clear conclusions. Moreover, in $22.5 \%$ of the patients, only one strain was studied and therefore, the results from the co-colonization of different strains per patient should be taken with caution. Similarly in 
a small number of patients, strains with non-attributable serotype were identified, which may belong to the serotype e' described by van der Reijden et al., since we did not use this specific primer, that was described after our samples were analyzed. ${ }^{62}$ Furthermore, the stratification used according to the patient's clinical diagnosis should also be taken with caution since different clinicians, not using uniform criteria, did the diagnosis. In spite of this, the study showed the high variability in the genetic variance of $A$. actinomycetemcomitans, which has been also reported in similar studies. This variability may be explained, in part, by the different bacterial detection techniques used in the different laboratories, but also due to differences in ethnicity, geographic location and the periodontal condition of the populations sampled. Further studies should evaluate whether the presence of certain pathogenic bacterial species is associated with periodontitis and attachment loss in some population groups but not in others, depending on the presence of specific virulence traits.

In conclusion, this research has evidenced that, in samples from a group of Spanish patients with periodontitis, the most common A. actinomycetemcomitans serotypes found were "b" and "a", while "e" and " $\mathrm{f}$ " were not detected. The genes responsible for the codification of leukotoxin were detected in all the strains, although none belonging to the JP2 strain. The operon that codifies the $c d t$ was also detected in the majority of the samples $(65.8 \%)$.

\section{Acknowledgements}

We thank for their technical assistance Arancha Llama-Palacios, María José Marín, Itziar González and Ana O’Connor from Laboratory of Dental Research, University Complutense, Madrid. 


\section{References}

1. Rodenburg JP, van Winkelhoff AJ, Winkel EG, Goene RJ, Abbas F, de Graff J. Occurrence of Bacteroides gingivalis, Bacteroides intermedius and Actinobacillus actinomycetemcomitans in severe periodontitis in relation to age and treatment history. J Clin Periodontol 1990;17(6):392-399.

2. Ebersole JL, Sandoval MN, Steffen MJ, Cappelli D. Serum antibody in Actinobacillus actinomycetemcomitans-infected patients with periodontal disease. Infect Immun 1991;59(5):1795-1802.

3. Slots J, Ting M. Actinobacillus actinomycetemcomitans and Porphyromonas gingivalis in human periodontal disease: occurrence and treatment. Periodontol 2000 1999;20:82-121.

4. Report C. Consensus report. Periodontal diseases: pathogenesis and microbial factors. Ann Periodontol 1996;1:926-932.

5. Van der Velden U, Abbas F, Armand S, Loos BG, Timmerman MF, Van der Weijden GA, et al. Java project on periodontal diseases. The natural development of periodontitis: risk factors, risk predictors and risk determinants. $J$ Clin Periodontol 2006;33(8):540-548.

6. Kaplan JB, Schreiner HC, Furgang D, Fine DH. Population structure and genetic diversity of Actinobacillus actinomycetemcomitans strains isolated from localized juvenile periodontitis patients. J Clin Microbiol 2002;40(4):1181-1187.

7. Zambon JJ, Christersson LA, Slots J. Actinobacillus actinomycetemcomitans in human periodontal disease. Prevalence in patient groups and distribution of biotypes and serotypes within families. J Periodontol 1983;54(12):707-711.

8. Haffajee AD, Socransky SS. Microbial etiological agents of destructive periodontal diseases. Periodontol 2000 1994;5:78-111.

9. Asikainen S, Chen C, Slots J. Actinobacillus actinomycetemcomitans genotypes in relation to serotypes and periodontal status. Oral Microbiol Immunol 1995;10(2):6568.

10. Zambon JJ, Slots J, Genco RJ. Serology of oral Actinobacillus actinomycetemcomitans and serotype distribution in human periodontal disease. Infect Immun 1983;41(1):19-27.

11. van Winkelhoff AJ, Slots J. Actinobacillus actinomycetemcomitans and Porphyromonas gingivalis in nonoral infections. Periodontol 2000 1999;20:122-135.

12. Holtta P, Alaluusua S, Saarela M, Asikainen S. Isolation frequency and serotype distribution of mutans streptococci and Actinobacillus actinomycetemcomitans, and clinical periodontal status in Finnish and Vietnamese children. Scand J Dent Res 1994;102(2):113-119.

13. Celenligil H, Ebersole JL. Analysis of serum antibody responses to periodontopathogens in early-onset periodontitis patients from different geographical locations. J Clin Periodontol 1998;25(12):994-1002.

14. Dahlen G. Microbiology and treatment of dental abscesses and periodontalendodontic lesions. Periodontol 2000 2002;28:206-239.

15. Fine DH, Markowitz K, Furgang D, Fairlie K, Ferrandiz J, Nasri C, et al. Aggregatibacter actinomycetemcomitans and its relationship to initiation of localized aggressive periodontitis: longitudinal cohort study of initially healthy adolescents. $J$ Clin Microbiol 2007;45(12):3859-3869.

16. Yang HW, Asikainen S, Dogan B, Suda R, Lai CH. Relationship of 
Actinobacillus actinomycetemcomitans serotype $\mathrm{b}$ to aggressive periodontitis: frequency in pure cultured isolates. Journal of periodontology 2004;75(4):592-599.

17. Saarela M, Asikainen S, Alaluusua S, Pyhala L, Lai CH, Jousimies-Somer H. Frequency and stability of mono- or poly-infection by Actinobacillus actinomycetemcomitans serotypes a, b, c, d or e. Oral Microbiol Immunol 1992;7(5):277-279.

18. Mombelli A, Gmur R, Lang NP, Corbert E, Frey J. Actinobacillus actinomycetemcomitans in Chinese adults. Serotype distribution and analysis of the leukotoxin gene promoter locus. J Clin Periodontol 1999;26(8):505-510.

19. Chung HJ, Chung CP, Son SH, Nisengard RJ. Actinobacillus actinomycetemcomitans serotypes and leukotoxicity in Korean localized juvenile periodontitis. J Periodontol 1989;60(9):506-511.

20. Asikainen S, Lai CH, Alaluusua S, Slots J. Distribution of Actinobacillus actinomycetemcomitans serotypes in periodontal health and disease. Oral Microbiol Immunol 1991;6(2):115-118.

21. Poulsen K, Theilade E, Lally ET, Demuth DR, Kilian M. Population structure of Actinobacillus actinomycetemcomitans: a framework for studies of disease-associated properties. Microbiology 1994;140 ( Pt 8):2049-2060.

22. Haubek D, Poulsen K, Asikainen S, Kilian M. Evidence for absence in northern Europe of especially virulent clonal types of Actinobacillus actinomycetemcomitans. $J$ Clin Microbiol 1995;33(2):395-401.

23. Baehni PC, Tsai CC, McArthur WP, Hammond BF, Shenker BJ, Taichman NS. Leukotoxic activity in different strains of the bacterium Actinobacillus actinomycetemcomitans isolated from juvenile periodontitis in man. Archives of oral biology 1981;26(8):671-676.

24. Haubek D, Ennibi OK, Poulsen K, Vaeth M, Poulsen S, Kilian M. Risk of aggressive periodontitis in adolescent carriers of the JP2 clone of Aggregatibacter (Actinobacillus) actinomycetemcomitans in Morocco: a prospective longitudinal cohort study. Lancet 2008;371(9608):237-242.

25. Yamano R, Ohara M, Nishikubo S, Fujiwara T, Kawamoto T, Ueno Y, et al. Prevalence of cytolethal distending toxin production in periodontopathogenic bacteria. $J$ Clin Microbiol 2003;41(4):1391-1398.

26. Ahmed HJ, Svensson LA, Cope LD, Latimer JL, Hansen EJ, Ahlman K, et al. Prevalence of cdtABC genes encoding cytolethal distending toxin among Haemophilus ducreyi and Actinobacillus actinomycetemcomitans strains. $J$ Med Microbiol 2001;50(10):860-864.

27. Tan KS, Woo CH, Ong G, Song KP. Prevalence of Actinobacillus actinomycetemcomitans in an ethnic adult Chinese population. J Clin Periodontol 2001;28(9):886-890.

28. Contreras A, Rusitanonta T, Chen C, Wagner WG, Michalowicz BS, Slots J. Frequency of 530-bp deletion in Actinobacillus actinomycetemcomitans leukotoxin promoter region. Oral Microbiol Immunol 2000;15(5):338-340.

29. Haraszthy VI, Hariharan G, Tinoco EM, Cortelli JR, Lally ET, Davis E, et al. Evidence for the role of highly leukotoxic Actinobacillus actinomycetemcomitans in the pathogenesis of localized juvenile and other forms of early-onset periodontitis. $J$ Periodontol 2000;71(6):912-922.

30. Haubek D, Dirienzo JM, Tinoco EM, Westergaard J, Lopez NJ, Chung CP, et al. Racial tropism of a highly toxic clone of Actinobacillus actinomycetemcomitans associated with juvenile periodontitis. J Clin Microbiol 1997;35(12):3037-3042.

31. Haubek D, Poulsen K, Westergaard J, Dahlen G, Kilian M. Highly toxic clone of 
Actinobacillus actinomycetemcomitans in geographically widespread cases of juvenile periodontitis in adolescents of African origin. J Clin Microbiol 1996;34(6):1576-1578.

32. Paju S, Carlson P, Jousimies-Somer H, Asikainen S. Heterogeneity of Actinobacillus actinomycetemcomitans strains in various human infections and relationships between serotype, genotype, and antimicrobial susceptibility. J Clin Microbiol 2000;38(1):79-84.

33. Armitage GC. Development of a classification system for periodontal diseases and conditions. Ann Periodontol 1999;4(1):1-6.

34. Mombelli A, McNabb H, Lang NP. Black-pigmenting gram-negative bacteria in periodontal disease. II. Screening strategies for detection of P. gingivalis. J Periodontal Res 1991;26(4):308-313.

35. Syed SA, Loesche WJ. Survival of human dental plaque flora in various transport media. Appl Microbiol 1972;24(4):638-644.

36. Alsina M, Olle E, Frias J. Improved, low-cost selective culture medium for Actinobacillus actinomycetemcomitans. J Clin Microbiol 2001;39(2):509-513.

37. Brown LF, Beck JD, Rozier RG. Incidence of attachment loss in communitydwelling older adults. J Periodontol 1994;65(4):316-323.

38. Lau L, Sanz M, Herrera D, Morillo JM, Martin C, Silva A. Quantitative realtime polymerase chain reaction versus culture: a comparison between two methods for the detection and quantification of Actinobacillus actinomycetemcomitans, Porphyromonas gingivalis and Tannerella forsythensis in subgingival plaque samples. $J$ Clin Periodontol 2004;31(12):1061-1069.

39. Sanz M, van Winkelhoff AJ, Herrera D, Dellemijn-Kippuw N, Simon R, Winkel E. Differences in the composition of the subgingival microbiota of two periodontitis populations of different geographical origin. A comparison between Spain and The Netherlands. Eur J Oral Sci 2000;108(5):383-392.

40. Preus HR, Anerud A, Boysen H, Dunford RG, Zambon JJ, Loe H. The natural history of periodontal disease. The correlation of selected microbiological parameters with disease severity in Sri Lankan tea workers. J Clin Periodontol 1995;22(9):674-678. 41. Ogunsalu C, Daisley H, Akpaka PE. Prevalence and antimicrobial susceptibility pattern of pathogens isolated from patients with juvenile periodontitis in Jamaica: a prospective multi-centre study of 15 cases over a 15-year period. West Indian Med J 2011;60(2):235-239.

42. Stingu CS, Jentsch H, Eick S, Schaumann R, Knofler G, Rodloff A. Microbial profile of patients with periodontitis compared with healthy subjects. Quintessence Int 2012;43(2):e23-31.

43. Aberg CH, Kwamin F, Claesson R, Johansson A, Haubek D. Presence of JP2 and Non-JP2 Genotypes of Aggregatibacter actinomycetemcomitans and attachment loss in adolescents in Ghana. J Periodontol 2012;83(12):1520-1528.

44. Papapanou PN, Baelum V, Luan WM, Madianos PN, Chen X, Fejerskov O, et al. Subgingival microbiota in adult Chinese: prevalence and relation to periodontal disease progression. J Periodontol 1997;68(7):651-666.

45. Papapanou PN, Teanpaisan R, Obiechina NS, Pithpornchaiyakul W, Pongpaisal $\mathrm{S}$, Pisuithanakan S, et al. Periodontal microbiota and clinical periodontal status in a rural sample in southern Thailand. Eur J Oral Sci 2002;110(5):345-352.

46. Chen $\mathrm{C}$, Wang $\mathrm{T}$, Chen W. Occurrence of Aggregatibacter actinomycetemcomitans serotypes in subgingival plaque from United States subjects. Mol Oral Microbiol 2010;25(3):207-214.

47. Bandhaya P, Saraithong P, Likittanasombat K, Hengprasith B, Torrungruang K. Aggregatibacter actinomycetemcomitans serotypes, the JP2 clone and cytolethal 
distending toxin genes in a Thai population. J Clin Periodontol 2012;39(6):519-525.

48. Roman-Torres CV, Aquino DR, Cortelli SC, Franco GC, Dos Santos JG, Corraini P, et al. Prevalence and distribution of serotype-specific genotypes of Aggregatibacter actinomycetemcomitans in chronic periodontitis Brazilian subjects. Arch Oral Biol 2010;55(3):242-248.

49. Corraini P, Baelum V, Pannuti CM, Romito GA, Aquino DR, Cortelli SC, et al. Subgingival microbial profiles as diagnostic markers of destructive periodontal diseases: a clinical epidemiology study. Acta Odontol Scand 2013;71(2):289-299.

50. Kim TS, Kang NW, Lee SB, Eickholz P, Pretzl B, Kim CK. Differences in subgingival microflora of Korean and German periodontal patients. Arch Oral Biol 2009;54(3):223-229.

51. Kim TS, Frank P, Eickholz P, Eick S, Kim CK. Serotypes of Aggregatibacter actinomycetemcomitans in patients with different ethnic backgrounds. J Periodontol 2009;80(12):2020-2027.

52. Sakellari D, Katsikari A, Slini T, Ioannidis I, Konstantinidis A, Arsenakis M. Prevalence and distribution of Aggregatibacter actinomycetemcomitans serotypes and the JP2 clone in a Greek population. J Clin Periodontol 2011;38(2):108-114.

53. Psoter WJ, Ge Y, Russell SL, Chen Z, Katz RV, Jean-Charles G, et al. PCR detection of Streptococcus mutans and Aggregatibacter actinomycetemcomitans in dental plaque samples from Haitian adolescents. Clin Oral Investig 2011;15(4):461-469. 54. Jentsch H, Cachovan G, Guentsch A, Eickholz P, Pfister W, Eick S. Characterization of Aggregatibacter actinomycetemcomitans strains in periodontitis patients in Germany. Clin Oral Investig 2012;16(6):1589-1597.

55. Listgarten MA, Lai CH, Evian CI. Comparative antibody titers to Actinobacillus actinomycetemcomitans in juvenile periodontitis, chronic periodontitis and periodontally healthy subjects. J Clin Periodontol 1981;8(3):155-164.

56. Dogan B, Saarela MH, Jousimies-Somer H, Alaluusua S, Asikainen S. Actinobacillus actinomycetemcomitans serotype e--biotypes, genetic diversity and distribution in relation to periodontal status. Oral Microbiol Immunol 1999;14(2):98103.

57. Yoshida Y, Suzuki N, Nakano Y, Shibuya K, Ogawa Y, Koga T. Distribution of Actinobacillus actinomycetemcomitans serotypes and Porphyromonas gingivalis in Japanese adults. Oral Microbiol Immunol 2003;18(3):135-139.

58. Teixeira RE, Mendes EN, Roque de Carvalho MA, Nicoli JR, Farias Lde M, Magalhaes PP. Actinobacillus actinomycetemcomitans serotype-specific genotypes and periodontal status in Brazilian subjects. Can J Microbiol 2006;52(3):182-188.

59. Ennibi OK, Benrachadi L, Bouziane A, Haubek D, Poulsen K. The highly leukotoxic JP2 clone of Aggregatibacter actinomycetemcomitans in localized and generalized forms of aggressive periodontitis. Acta Odontol Scand 2012;70(4):318-322.

60. Haubek D, Poulsen K, Kilian M. Microevolution and patterns of dissemination of the JP2 clone of Aggregatibacter (Actinobacillus) actinomycetemcomitans. Infect Immun 2007;75(6):3080-3088.

61. Fabris AS, DiRienzo JM, Wikstrom M, Mayer MP. Detection of cytolethal distending toxin activity and cdt genes in Actinobacillus actinomycetemcomitans isolates from geographically diverse populations. Oral Microbiol Immunol 2002;17(4):231-238.

62. van der Reijden WA, Brunner J, Bosch-Tijhof CJ, van Trappen S, Rijnsburger MC, de Graaff MP, et al. Phylogenetic variation of Aggregatibacter actinomycetemcomitans serotype e reveals an aberrant distinct evolutionary stable lineage. Infect Genet Evol 2010;10(7):1124-1131. 
